\title{
Study on urban roadside landscape with the procedure of permanent urban planning
}

\author{
Mohammadreza Noghsan Mohammadi, Parisa Rismanbaf* \\ Arts and Architecture Faculty, Yazd University, Yazd, Iran. \\ Email address: \\ mrnm@yahoo.com (M. N. Mohammadi),parisa_rismanbaf@yahoo.com (P. Rismanbaf)
}

\section{To cite this article:}

Mohammadreza Noghsan Mohammadi, Parisa Rismanbaf. Study on Urban Roadside Landscape with the Procedure of Permanent Urban Planning. International Journal of Intelligent Information Systems. Special Issue: Research and Practice in Architecture and Urban Studies in Developing Countries. Vol. 3, No. 2-1, 2015, pp. 31-35. doi: 10.11648/j.ijsts.s.2015030201.17

\begin{abstract}
In past, the urban roadside was the connector joint of the inside manmade landscape and outside natural landscape. Disorganization of spatial hierarchical in physical system of the cities due to be modernized, has caused that the urban roadside landscapes have been unidentified and encountered to disorganization. The urban roadside landscape is the first space that the travelers are visiting. Therefore, this space must be effective information of group minds and their mental imaginations. Later, through expansion of cities to harbor areas, the locations which those squares and boulevards where, are urban roadside landscape now, will be located therein, and will be further converted to an urban difficulty. Therefore, a type of foresight is necessary for decreasing the difficulties of the permanent future structure. In this article, urban landscapes are studied with consideration to the permanency principles. Results of the research are presented as strengthening components of permanent development dimensions in order to design the urban roadside landscapes. This research is in the type of fundamental and the research methodology type is descriptive-analytical.
\end{abstract}

Keywords: Urban Roadside Landscape, Permanency, Qualitative Components

\section{Introduction}

Through a review on previous and urban structures, we know that urban roadside landscape has an important role on making identification for a city and they made outstanding imagination of the city. Fast changes rose from being modernization of the recent years, has caused surprise revolutions. Speed of these changes was in such a way that the societies did not have the opportunity to introduction and analysis of modern phenomena. Cities have been extended without examination and in this regard, urban roadside landscape has been forgotten. Urban roadside landscape has indicated the best sample of permanency. Consideration to local ecological limitations, appropriate and adapted development with nature, artistic use of water and plant for making the air refresh and providing a favorite landscape, public spaces, are some samples of factors effective in this permanency. But, unfortunately nowadays the urban roadside landscapes are currently made by old and unsuitable buildings that not only respond to an operational necessity, but also there is no difference that indicates urban roadside landscape, and has granted invisible edges to the city. Urban planning not only has caused impermanent status for cities through following the development classic template and blindly following from formulaic templates of urban development without paying attention to local specifications, but also it has instability for surrounding regions. It is the time for knowing the roadside landscape and find the effect of roadside landscape in a permanent city through accepting this matter that a city is a homogenous physics and containing of multilateral relationships between the forces.

\section{Definition of Urban Roadside Landscape}

The manner to enter to every space, or on the word, entrance of every space has a special situation in people minds. Entrance of every space is the first space that total specifications of the space, ceremonies, private and general limitations and other specifications of the space are identified. In fact through providing an entrance for a space (even a city or a parish or a building) that space will find an identification for its residences, strengthened, marked and shown more alive [1], as we think that city has an entity that lives such as other entities and grows. In order to enter to an organized and alive 
complex of a city, we must pass the joint between urban physic and suburb structure. This middle member is not suburb or city, but it is a transferring step between these two parts. Size of this member has close dependence to spread of city limitation and volume of traffic (travellers and goods) [2]. In some cases, entrance from one space to another space is clear and it can happen in the simplest manner through a vertical surface. On the other hand, in a bigger urban scale, mostly entrance from a space to another space will happen with some differences between two spaces, or it happens gradually and needs to enter from one ore some mediator spaces. In natural environments, due to gradual change of natural environment, the process of exit from one space and enter to another space is gradually [3].

\section{Specifications of Urban Roadside Landscapes of Iran}

Perceptual and operational specifications of the urban roadside landscapes have previously been effected by culture, social customs and some activities that have been in that space. Of course it must be said that physical specifications of roadside landscape is so important in the most important role thereof, means physical relationship. In Table1, some Roadside Landscape specifications have been listed.

Table 1. Specifications of Roadside Landscapes

\begin{tabular}{l}
\hline Operational Specifications of \\
Former Roadside Landscape \\
\hline$*$ establishment of physical \\
relationship between two spaces \\
through the element of Gate \\
* Providing safety and supervision \\
on relationships through tower and \\
bulwark. \\
Guidance through the Gates \\
located at the direction of main \\
roads of the city and were \\
connected to the city center. \\
* Introducing the city (some \\
inscriptions over the important \\
Gates) \\
* Using the roadside landscapes in \\
daily activities through open \\
defined spaces against the gates.
\end{tabular}

Perceptual Specifications of Former Roadside Landscapes

* Invitation (due to social operation and being dynamic of open space against the city gates).

* Granting identification (making important the gate and its decorations and making the gate outstanding)

* Producing the entering sense (passing through a gate as a separator border of two spaces)

Making prepare for understanding the new space (open space against the gate with social operation)

* Establishment of perceptual and visual relationship between two spaces (presence of a gate and an activity current therein)
Perceptual and Operational Specifications of Nowadays Cities

* Urban Roadside Landscapes are mostly lack of identified and outstanding structure.

* Urban Roadside Landscapes are lack mostly of identification and cause visual and environmental difficulties for cities identifications.

* Some applications with unsuitable appearance such as repair shops, junks and warehouses form the urban roadside landscapes.

* If there would not be a special natural vision, there is not a special roadside landscape for making difference between the different cities.

* Guidance of new comers do not fulfilled well.

* Introducer signs of cities have been located in unsuitable locations with unsuitable qualification and size and are not easily seen.

* If there is some valuable elements, and historical and natural symbols, these elements have been lost among the visual and environmental disorders.

* Urban Roadside Landscapes mostly are lack of visual attraction and motivation for entering to the city.

* Due to lack of identified structure, entering feeling is not felt in this space for people.

* In the case of valuable natural elements such as plant coverage or being outstanding or variety of the shape of the land shapes in or around the urban roadside landscape, undesirable effect of environmental and visual difficulties will be decreased.

* In some urban roadside landscapes where are lack of beautiful natural landscape, negative effect of environmental and visual disorders are more visible.

* Because of being low of environmental qualification and some applications such as car repair shops and so on, in most entrances, its ability for some social activities have been lost.

\section{Organizing the Newly Roadside Urban Landscape}

Through observing the old urban structures of Iran, we can find that Roadside Urban Landscape was one of the urban structures that was located in its direction and connected the outside of the city to inside. Nowadays, the roadside landscape must be a part of urban structure and the location of converting the outside operations to inside operations and will renew the previous operational and visual operations of the city. On the other hand, due to spread of the current cities and speed of vehicles, that will cause to understand more space in a shorter time, city form must indicate and accept of the entering and if we will consider the outside area as a public space, and the inside of the city as a private space, roadside landscape must be able to produce a spatial surrounding in the time of entering to the city. On the other word, roadside landscape must be in the scale of current cities and may not be limited to a building or a gate. Also some operations that are located in the urban roadside landscape must respond to entrance necessities. But for those people who pass the city, manner of its localization must be observed that passing traffic would not be transferred into the city.

Attention must be paid to the urban roadside landscape as a place for converting of all types of movements. A place that types of movements and interurban vehicles will be converted to intercity movement in order to run fast the traffic and urban transportation system and consequently, movement disorders and different transport interrupts will decrease.

What we encounter as an urban roadside landscape has been caused some disorders for people behavioral system and happening some behavioral disorders too. It means that as these operations are for the entering people to the city and 
neglect to design of this space as a connector joint, has caused to sudden entering of people to the spaces in such a way that there would not be any chance for change or adaptation of behavior with new space. This lack of behavioral adaptation with new environment would have negative effect on environment and will be appeared as an abnormality [4]. The urban roadside landscape must have a spatial-physical superiority or lasting specifications [5]. But this physical disturbed spread has been so effective on the amount of safety in traffics. According to road accident statistics, more than $70 \%$ of the country road accidents have been in limitation of the first or last 30 -kilometer and more than $40 \%$ of the country road accidents have been in the limitation of the first or last 5-kilometre of the interurban roads. The related researches indicate that one of the most important factors of accidents in limitation of the urban roadside, has been impermissible constructions in the limitations, increase of the different applications and increment of the approaches [6].

\section{Social Permanency and Urban Roadside Landscape}

Economic, social and environmental dimensions contain three main dimensions of the permanent development. Development is permanent when it will be economically lasting, and will be socially acceptable and environmentally accurate. Because, any type of activity that are fulfilled by human (social), are mostly due to an motivation for interest and income (economically) that are fulfilled in nature and using the natural resources (environmental) [7].

One of the important operations of the gates in previous, is social application; previously the area around the gates was an urban and local space and a place for producing the social interactions and many of people came to this area for leisure time. Through renewing the urban roadside landscape meaning, we must pay attention to this matter that inner space may be a place for establishment of social relationships and social memories and will remain on people's mind and sometimes this common memories will cause social union, too that is one of the main columns of social permanency.

Table 2. Presentation of Components of Social Permanency Dimension for Urban Roadside Landscape

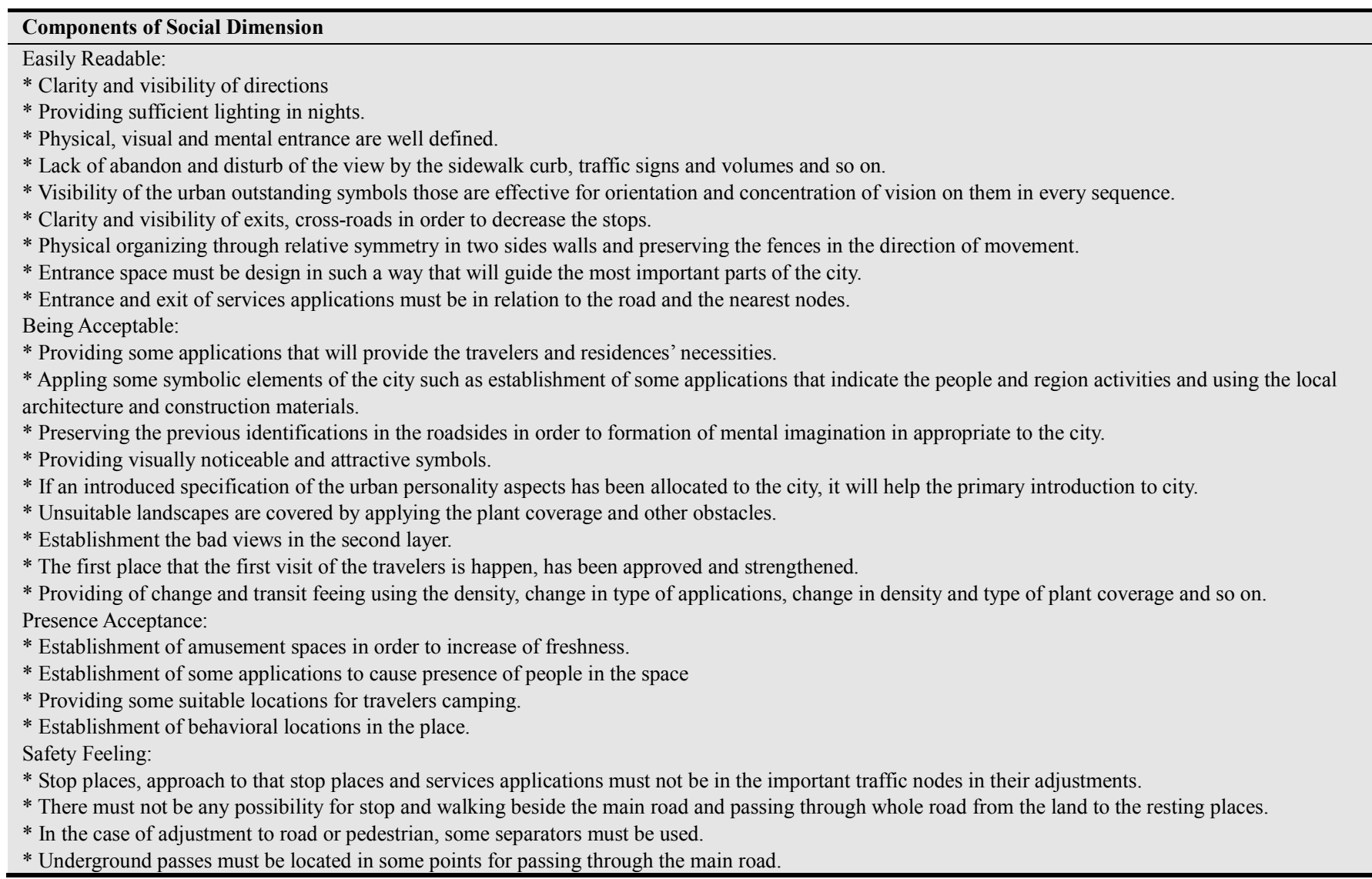

Therefore, urban roadside landscape must take service to travellers and provide enough information about all things that they will encounter with them. It must be a dynamic, active and flexible space for daily activities of people and a space for gathering people in national and religious ceremonies. Urban roadside landscape must be a location for leisure time of the residences and travellers and there will be amusement services therein. One of the obvious specifications of the urban roadside landscape is easily readable. The person needs to fast distinguish of directions and making decision in addition to provide his (her) needs. Easily readable will cause not only decrease of traffic in roadside landscape but also obvious 
mental imagination in people, will cause a safe feeling in supervisor. In Table2, some components of social permanency dimensions have been presented.

\section{Economic Permanency and Urban Roadside Landscape}

One of the other important applications was economical application. Previously, one of the most important resources of the governments' incomes has been taxes and charges that were received for importation or exportation goods. These charges were received beside the gates from the merchants and owners of the commercial goods, because the gates were the only passage where the goods were imported or exported. Nowadays, large amount of services applications and peddlers in the urban roadside indicate that supply and demand (economical exchanges) are a lot in the urban roadside, and this space has a high potential for attraction the capital and even it may have important and effective role for providing occupation for the people of the suburb and development of the economic problems and support the city.

Through studying on the purchasers' behavior, the sellers have reported that through increment of the qualification of natural elements of the city, tendency to purchase will increase too. In the study on the relationship between nature and commerce, the purchasers declared that they are eager to pay more 9 to $12 \%$ for the goods and services in commercial regions with high qualification of natural space [8]. Some components of dimension components have been presented in Table 3.

Table 3. Submission of the Components of Economic Permanency for the Urban Roadside Landscape

Components of Economic Dimension
* Presence of applications indicator of the social-economic activities of the cities.
* Establishment of some locations in order to presence of peddlers.
* Establishment of some locations for sale of local products and some weekly, seasonal bazaars.
* Organizing some applications considering to adaptation, adjustment and favorite standards.
* Increase of economic efficiency through strengthening the applicable and leisure chances and capabilities for entrance landscape.

Table 4. Environmental Permanency Dimension Components for Urban Roadside Landscape

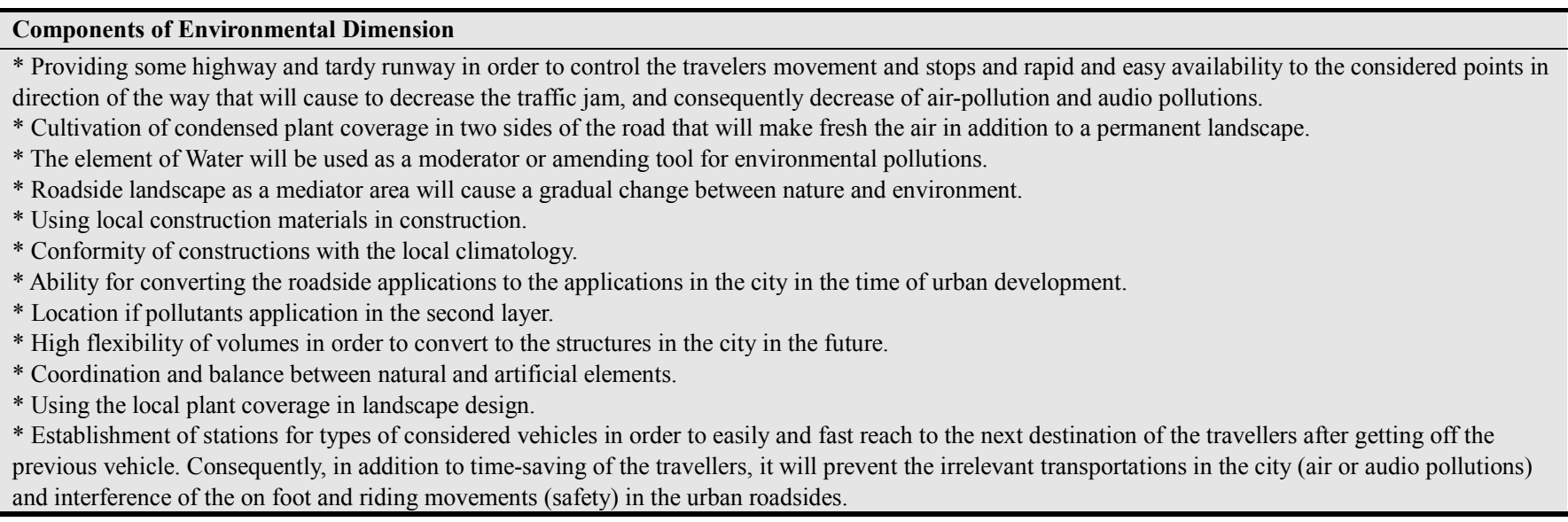

\section{Environmental Permanency and Urban Roadside Landscape}

Cities are established in the bed of nature and relationship of the city with its environment is such as the relationship between container and contents. Automatically spread and irregular and without-plan development of cities have caused to weaken the form and contents of the urban roadside landscape. As the roadside landscape of cities is considered as one of the urban landscapes, even we can imagine it as the first space for encountering with urban phenomena that provides the first imagination in the travelers' minds, paying attention to the meaning of roadside landscape and common templates of spatial relationship of this phenomena is the most important studies in paying attention to the urban spaces procedure.

Previously, in order to definition the urban roadside landscape, some artificial elements such as gate, ramparts, fence and ditch were used and definition of space with natural elements did not have any meaning as its current meaning, but after changes in movement speed and type of vehicles, we can use some natural elements, specially plants, for definition of roadside landscape and after designing the manner of cultivation of the trees in the roadside direction, we will prepare the travellers and visitors for having a new experience of the city, and instead of movement through old buildings, deserted sites, industrial regions or even some dried and uncultivated directions that are suddenly connected to urban structure, we will provide a direction for passing through a space full of trees that due to the type, form, density and organization of their establishment beside each other, they can identify the urban roadside landscape and this direction will be distinguished from other directions [9]. In table 4, Some components of environmental permanency dimension have 
been presented.

\section{Discussion and Conclusion}

Nowadays, weak performance in urban roadside landscape raised from unsuitable design and establishment without planning, has caused that the urban roadside landscape would not respond to the travellers and residences' necessities. Movement from the out of the city into the city must be rhythmic and harmonic. In order to provide this movement and preventing a sudden transfer, both inside and outside spaces of the city must be identified and the third space that is roadside landscape of the city must be as a joint between these two spaces and in addition to convert these two spaces, it must have an independent entity. All designs and actions fulfilled in these three domains must be appropriate with consideration to the position and expects of each domain, consequently roadside landscape will be flexible and successful. The main objective of this research is exploitation of the components of triplet social, economic and environmental dimensions in order to gain a permanent roadside landscape. We can use these components in strengthening the permanency indexes in the urban roadside landscape. Necessities for fulfillment of urban roadside landscape may be organized in the current urban planning based on permanency components. Permanent development and city planning have a close relationship with each other. Therefore, a suitable plan (project) for urban roadside landscape is not considered as a necessary and sufficient condition for permanency; generally all existing performances in other domains such as control and supervision, environmental planning and so on will be effective on gaining a permanent development. Gaining to a permanent roadside landscape will be possible when the local associations will be responsible for their environment and for this reason, a political power must be given to them. Consequently, an effective public partnership may be a base for suitable design.

\section{References}

[1] A, Christopher, "A patern language", translated by Reza KarbalaeiNouri, City Planning and Architecture Studies and Research Center, Ministry of Housing and City Planning, Tehran, Iran, 2008, p.277

[2] A, Ghavampour, "A new regard to the role and position of urban roadside landscape", Payame-Sabz Monthly Periodical, Version No.54,2006, p.24.

[3] H, Bahreini and N, Ali TalebBaboli, "Compilation of the principles and regulations of urban roadside landscape", Ecologist, Version No. 8, University of Tehran, 2003, p.14

[4] J, Pakzad, "Gidline for urban landscape in Iran", Tehran, Ministry of Housing and City Planning, City Planning and Architecture Deputyship, 2007, p.9.

[5] N, Ghazizadeh, "EmamzadehHashem, a known imagination", Iran Landscape Architecture Magazine, Tehran, 1999, p.14.

[6] S, Afandizadeh, R, GolshanKhavas, "Urban roadside safe landscape" Transportation Research Magazine, third year, version No.4, 2006, p.235.

[7] S, Zahedi and G, Najafi, "Conceptual extent of peramnent development", Modarres Quarterly Periodical, 10th Year, version No.4, 2006, p.24.

[8] Karen K. Dixon, "Benefits and risks of urban roadside landscape: finding a livable, balanced response", Seattle, Washington, 2007, p.6.

[9] F, Gharib, "Organizing regulations and standards for urban roadside landscape", Fine Arts Magazine, Version No. 15, 2003 , p.35. 